\title{
Long-Period Ground Motion Observations along Two Linear Profiles from the 26 December 2006 Pingtung Offshore Earthquakes
}

\author{
Kou-Cheng Chen ${ }^{1, *}$, Jeen-Hwa Wang ${ }^{1}$, and Ta-Liang Teng ${ }^{2}$ \\ ${ }^{1}$ Institute of Earth Sciences, Academic Sinica, Taipei, Taiwan, ROC \\ ${ }^{2}$ Department of Geosciences, University of Southern California, Los Angeles USA
}

Received 30 January 2008, accepted 26 September 2008

\begin{abstract}
Strong ground motions generated by the 26 December 2006 Pingtung offshore twin earthquakes were analyzed to investigate the characteristics of ground motions along two linear profiles: one lines up the twin epicenters to the Taipei basin across the western side of the Central Range which is the backbone of Taiwan, and the other from the twin epicenters to the Lanyang basin along the Longitudinal Valley (LV). The attenuation relationship of the horizontal peak ground acceleration (PGA) as a function of distance derived by Lin and Lee (2008) fits the observed horizontal PGA data reasonably well along the two linear profiles for both events. However, the horizontal PGA and PGV of long-period $(>1 \mathrm{sec})$ ground motions are anomalously high in an area with a length of $40 \mathrm{~km}$ extending northwards from the entrance into the LV and then decrease with increasing distance, suggesting a funneling effect of wavefield into a major fault valley. The anomalously high PGA and PGV of the long-period ground motions may also be the amplification of the thick soil and soft rocks in the fault zone. In addition, the long-period ground motions are amplified by a factor from 2 to 10 in the Taipei basin and Lanyang basin at the northern end of Taiwan which are about $350 \mathrm{~km}$ away from the source region. The long-period ground motions after the S-waves observed in the two basin areas are mainly composed of surface waves on the basis of the Rayleigh-type elliptical particle motions.
\end{abstract}

Key words: Pingtung offshore earthquakes, Long-period, Along two linear profiles, Rayleigh wave, Love wave, Particle motion Citation: Chen, K. C., J. H. Wang, and T. L. Teng, 2008: Long-period ground motion observations along two linear profiles from the 26 December 2006 Pingtung offshore earthquakes. Terr. Atmos. Ocean. Sci., 19, 653-669, doi: 10.3319/TAO.2008.19.6.653(PT)

\section{INTRODUCTION}

Two large earthquakes $\left(\mathrm{M}_{\mathrm{L}}=6.96\right.$ and 6.99 , respectively) occurred, respectively, at 12:26 and 12:34 on 26 December 2006 offshore Pingtung in southwestern Taiwan (Fig. 1). Epicenters of these twin earthquakes are about $30 \mathrm{~km}$ apart. The CMT solutions from the Broadband Array in Taiwan for Seismology (BATS) of Institute of Earth Sciences, Academia Sinica and the Central Weather Bureau Seismic Network_BroadBand (CWBSN_BB) show normal faulting for the first earthquake and strike-slip faulting for the second one. The maximum peak ground accelerations (PGA) in the Pingtung area generated by the twin events were as high as 321 and $340 \mathrm{~cm} \mathrm{sec}^{-2}$, respectively. The twin earthquakes caused three residential structures collapsed, two persons killed, and 42 injured in the area, and severed several seafloor communication trunk cables offshore south-

\footnotetext{
* Corresponding author

E-mail: chenkc@earth.sinica.edu.tw
}

western Taiwan (see Hsu et al. 2008) causing a major disruption of data communication in Southeast Asia. The twin earthquakes have been the most destructive events in the Pingtung area since 1959 (Cheng et al. 1999).

Long-period strong ground motions caused by large earthquakes are the main factors responsible for seismic damages of large-scale structures, such as high-rise buildings, long bridges and big tank farms. Frankel et al. (1991) observed that the long-duration velocity and displacement of strong ground motions are mainly composed of surface waves formed at the edges of the basin from aftershocks of the Loma Prieta earthquake. Koketsu et al. (2005) found that a large number of large oil tanks at Tomakomai in the Yufutsu basin, Hokkaido, northern Japan, were damaged by the long-period ground motions during the 2003 Tokachi-oki earthquake, which was about $250 \mathrm{~km}$ away from the source region. Unusually large and prolonged shaking related to ground motions with periods of about $7 \mathrm{sec}$ were observed in 


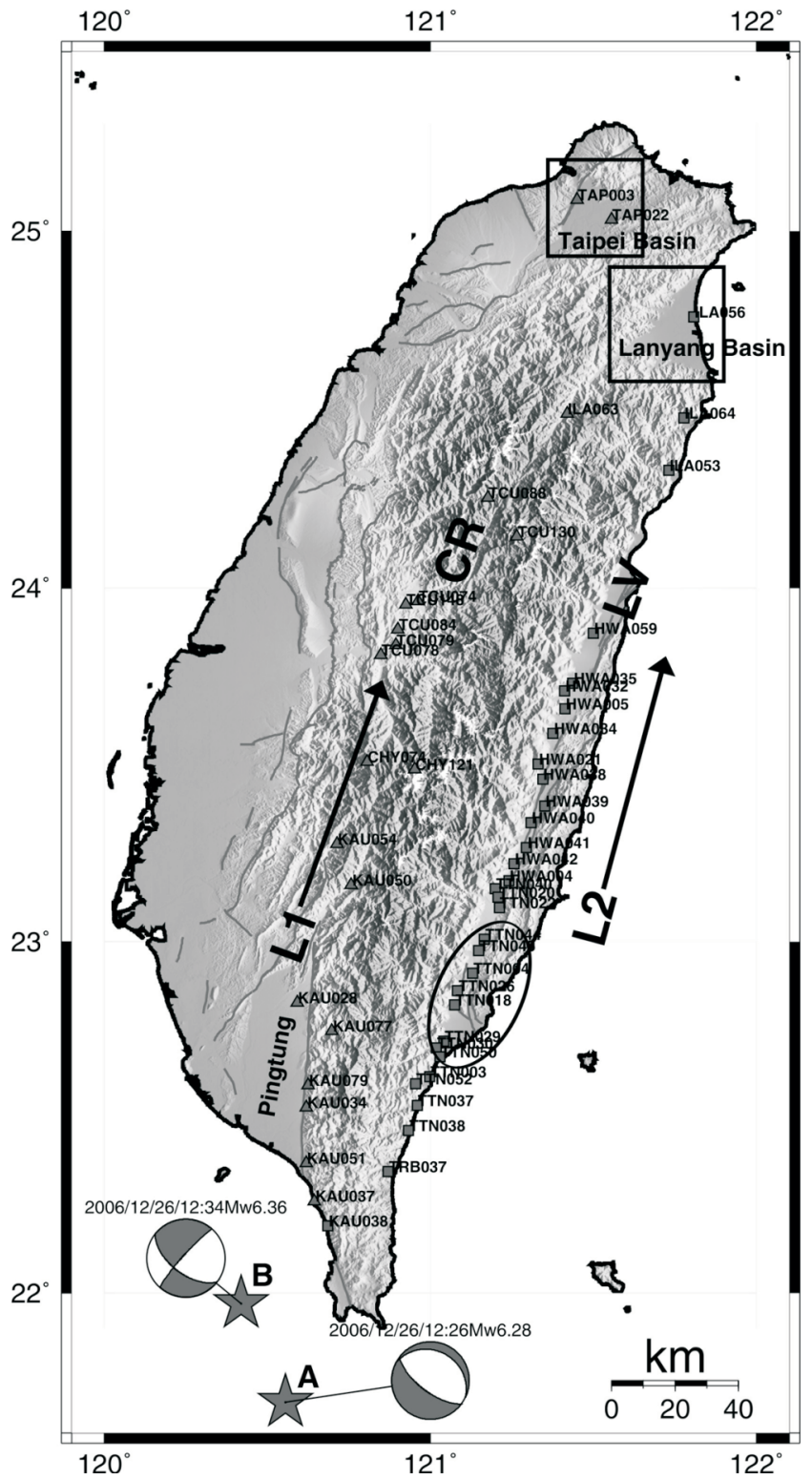

Fig. 1. Epicenters (stars) and focal mechanisms of 26 December 2006 Pingtung twin earthquakes (events A and B) offshore southwestern Taiwan. Solid lines depict the identified active faults in the area. Solid triangles and squares denote the seismic stations along lines L1 and L2 as mentioned in the text. The Taipei basin and the Lanyang basin are marked by two large open squares. The area with anomalously high PGA and PGV is marked by an ellipse.

central Tokyo during the $\mathrm{M}_{\mathrm{w}}$ 6.6 Niigata-ken Chuetsu earthquake of 23 October 2004 (Furumura and Hayakawa 2007). Hence, the study on characteristics of long-period ground motions in the sedimentary basins generated by large earthquakes is one of the most important issues for evaluating seismic hazard to large structures.

Surface waves which are an important component of long-period strong ground motions generated at the edge of a basin are frequently observed during distant earthquakes (e.g., Frankel et al. 1991, 2001; Koketsu et al. 2005; Miyake and Koketsu 2005; Furumura and Hayakawa 2007). Although there is no report on damages directly caused by surface waves during the 1999 Chi-Chi earthquake, longperiod surface waves were excited in the western coastal plain of central Taiwan (Chang et al. 2002; Wang et al. 2006). From numerical simulations, Chang et al. (2002) concluded that the excitation of surface waves during the 1999 Chi-Chi earthquake is mainly controlled by the nearsurface fault rupture, and the rupture velocity would strongly control the duration of surface waves. The short-period fundamental-mode Rayleigh waves from the strong-motion data have been used to infer the shallow crustal structure in the Taiwan region (Chung and Yeh 1997; Huang et al. 2003).

The Pingtung offshore twin earthquakes were, respectively, well recorded by 446 and 489 CWB's free-field strong motion stations (Wu et al. 2008). The strong-motion seismograms generated by the two events provide valuable information for the studies of the characteristics of ground motions across the Central Range and through the Longitudinal Valley to the two sedimentary basins which are located in northern Taiwan about $350 \mathrm{~km}$ away from the sources (Fig. 1). Two dense linear strong-motion profiles are extracted from the CWB free-field station database. In addition, there are high-rise buildings, major communication and transportation systems, and large-scale structures along these two profiles especially in the Taipei basin.

The Taipei basin is a triangular-shaped alluvium basin filled with the Quaternary unconsolidated sediments overlying the Tertiary basement (Wang-Lee and Lin 1987; Chang et al. 1998). Lin (2001) reported that the sediments thicken northwestward from a thin basin margin in the southeast to about $700 \mathrm{~m}$ in the northwest. From shallow seismic reflections, Wang et al. (2004) mapped the basement shape, the layer structures, and the velocity model of the basin. The Lanyang basin, also known as Lanyang plain, is underlain by two layers of recent alluvium, Pleistocene strata and the Miocene basement (Chiang 1976). The thickness of overlying structure layers thickens northeastward to about $1400 \mathrm{~m}$ along the central part of Lanyang basin and thins outward to the NW margins of the basin.

In past two decades, although only minor damage due to earthquakes in the Lanyang basin, the area is frequently attacked by moderate to large earthquakes. Many buildings in the Taipei basin collapsed or damaged during numerous distant earthquakes (Wang 2008), such as the Hualien offshore earthquakes of 20 May and 14 November 1986 (Chen and Wang 1988), the Chi-Chi earthquake of 21 September 1999 (Shin and Teng 2001; Chen et al. 2002), and the Haulien offshore earthquake of 31 March 2002 (Chen 2003). Studies of the characteristics of long-period ground motions in these two basins are therefore important for assessing the seismic hazards where large population resides.

In this study, the "long period" means period longer than 
$1 \mathrm{sec}$. An attempt is made here to first analyze the characteristics of ground motions recorded at stations along two linear profiles: one from the source area to the Taipei basin along the western side of the Central Range (CR in Fig. 1) and the other from the source area to the Lanyang basin along the Longitudinal Valley (LV in Fig. 1). Secondly, the strong motions recorded at two kinds of stations (one inside the basin and the other at the margin of or outside it). Seismic stations used are TAP003 (inside the basin with thick sediments) and TAP022 (at the margin of the basin with thin sediments) for the Taipei basin and ILA056 (inside) and ILA064 (outside) for the Lanyang basin. It is noted that in the followings the first and second of the twin earthquakes are denoted, respectively, by the A and B events.

Significant surface waves with a period of larger than $1 \mathrm{sec}$ could cause resonance in high-rise buildings of about 10-story or higher (Liu and Tsai 2007). In the two basins, a large number of such buildings have been constructed. Hence, the results of this study will be important for assessing seismic hazards in the two areas, especially in the Taipei basin.

\section{VARIATIONS OF GROUND MOTIONS WITH DISTANCE}

The twin events A and B were, respectively, well recorded by 446 and 489 CWB's free-field strong motion stations in the Taiwan region. In order to study the characteristics of long-period ground motions, two linear profiles shown in Fig. 1 are extracted from the CWB strong-motion database: L1 is the linear profile from station KAU038 to the Taipei basin across the western side of the Central Range (CR), and L2 from station TRB037 to the Lanyang basin along the Longitudinal Valley (LV). Figure 2 shows an example of the EW acceleration seismograms of the B event recorded at stations along L2. All traces are normalized to their maximum amplitudes and aligned to the P-arrivals. Site classification defined by Lee et al. (2001) is also shown at the beginning of each trace: a circle for Class-B site, none for Class-C site, and an asterisk for Class-D site. Classes B, C, and D represent rock, very dense soil and soft rock, and stiff soil sites, respectively. It is noted that the durations of most recorded accelerograms are less than $60 \mathrm{sec}$. Only the P- and S-wave trains can be clearly seen and the surface waves are very weak in the accelerograms recorded at stations along the Longitudinal Valley (Fig. 2a). Moreover, the long- period wave train after the S-waves obviously appears only in the accelerograms at station ILA056 inside the Lanyang basin.

The accelerograms are band-pass filtered with a frequency range from 0.05 to $0.5 \mathrm{~Hz}$ (Fig. 2b). It is noted that the $\mathrm{S}$-wave train with the maximum amplitude can clearly be seen for most filtered accelerograms. The amplitude of the later phase after the S-waves is very weak at stations in the distance out to about $230 \mathrm{~km}$. The filtered accelerograms after the S-wave display long-period, larger amplitude at the stations from the northern end of LV (HWA059) to the Lanyang basin (ILA056).

The horizontal peak ground acceleration (PGA) as a function of distance for the twin events are shown in Fig. 3.
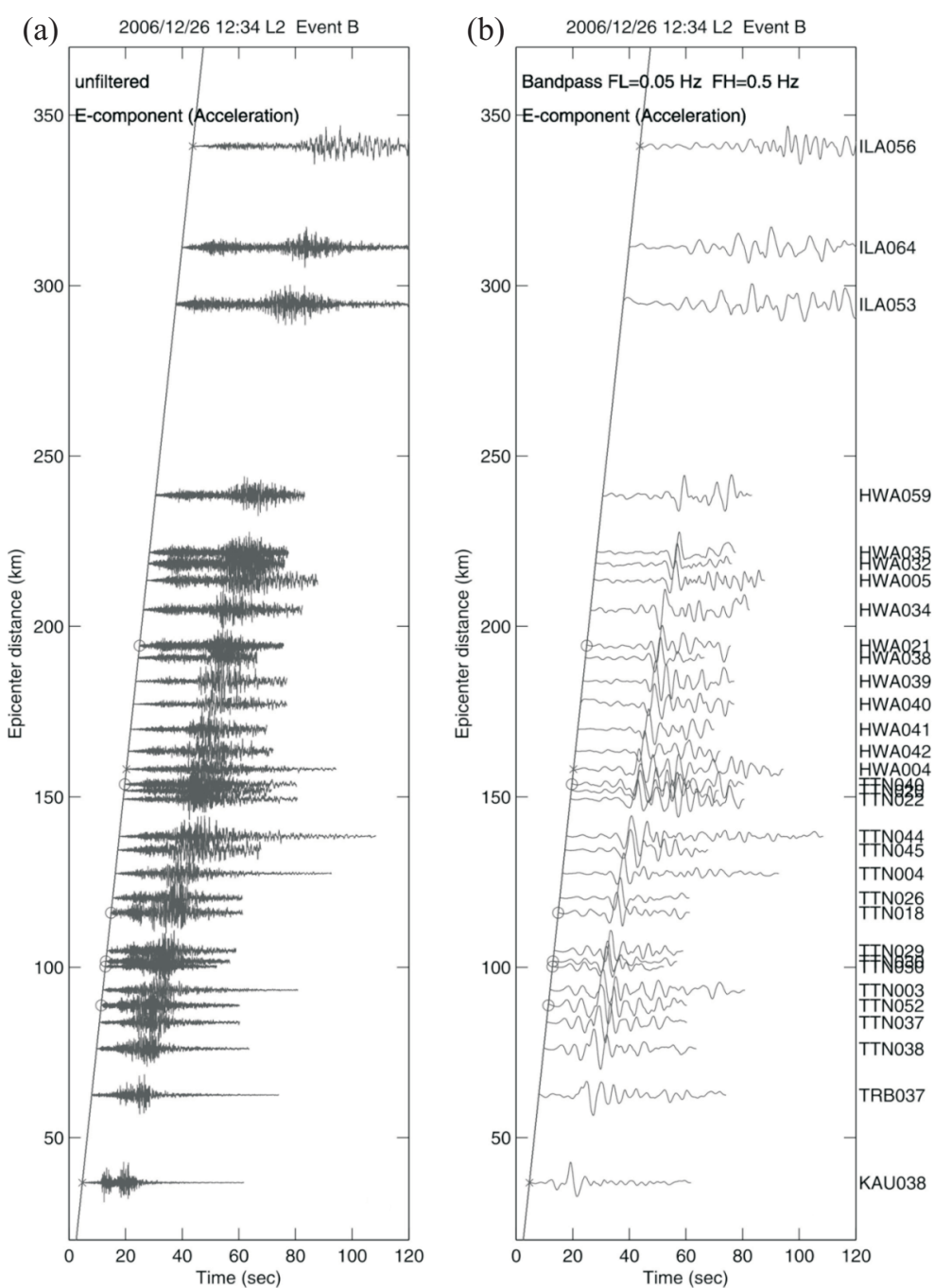

Fig. 2. (a) The original EW-component acceleration seismograms for the B event recorded at the stations along L2 as shown in Fig. 1 and (b) the related filtered acceleration waveforms in the frequency band of $0.05-0.5 \mathrm{~Hz}$. Station names are given at the right panel. All the traces are aligned to the P-arrivals and normalized to their maximum amplitudes. Site classification defined by Lee et al. (2001) is also shown at the beginning of each trace: a circle for a Class-B site, none for a Class-C site, and an asterisk for a Class-D site. 

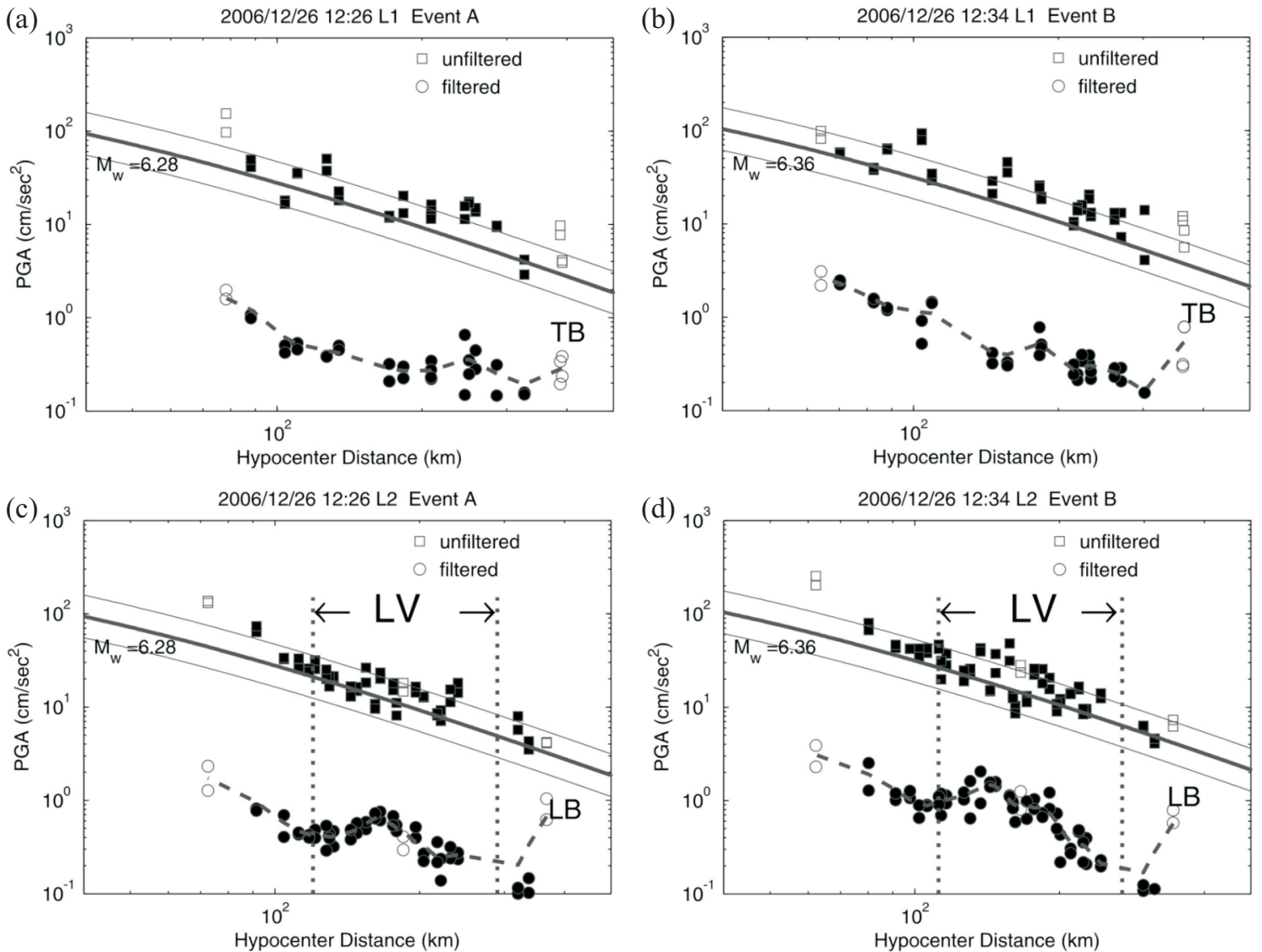

Fig. 3. Horizontal PGA as a function of distance: (a) and (b) along L1 for the A and B events and (c) and (d) along L2 for the two events. The squares and circles in each panel denote, respectively, unfiltered and filtered PGA. The solid and blank symbols indicate rock-type (Class-B and -C) and soil-type (Class-D and -E) sites, respectively. The thick and thin solid lines, respectively, depict the PGA attenuation curve and the standard deviation inferred by Lin and Lee (2008) for rock sites. The dashed line denotes the smoothing curve for the filtered PGA. Note that in addition to the amplification in the Taipei basin (TB) and the Lanyang basin (LB), the filtered PGA of both twin events show anomalously high values along the LV.

The stations sites are re-classified to two types (Lin and Lee 2008): one including the Class- $\mathrm{B}$ and $-\mathrm{C}$ rock sites and the other consisting of the Class-D and -E soil sites. As shown in Fig. 3, most sites in use are classified as the rock sites (solid symbols), and only few as the soil sites (open symbols). The soil sites are located both near epicenters and within the basins. The PGA attenuation relationship and its standard deviation for rock sites inferred by Lin and Lee (2008) are also plotted in Fig. 3. Along L1, most of the observed horizontal PGA data for the A (Fig. 3a) and B (Fig. 3b) events are higher than the predicted values. Along L2, most of the observed horizontal PGA data for the A (Fig. 3c) and B (Fig. 3d) events are within one standard deviation of the mean attenuation curve.

The horizontal PGA filtered from 0.05 to $0.5 \mathrm{~Hz}$ as a function of distance for the twin events are also shown in Fig. 3. Site amplifications are obviously observed at the stations inside the Taipei basin (Figs. 3a, b) and the Lanyang basin (Figs. 3c, d). In addition to the basin effect, the filtered PGA data for both two events at the stations along L1 somewhat decrease with increasing distance (see Figs. 3a, b). At the stations along L2, the filtered PGA abruptly becomes high from about 120 to $160 \mathrm{~km}$ along the LV for the A event (Fig. 3c) and from about 100 to $140 \mathrm{~km}$ for the B event (Fig. 3d), and then gradually decreases with increasing distance. The two areas with anomalously high PGA are close to each other. They are about $40 \mathrm{~km}$ northwards from the southern end (entrance) of the LV and are denoted by an ellipse in Fig. 1. It is noted that the decrease in the filtered PGA with increasing distance is smaller at the stations to the south of the southern end of the LV than at those along the LV. In addition, a comparison of the filtered waveforms at the stations between outside and inside the Lanyang basin (Figs. 3c, d) shows that the filtered PGA inside the basin can be amplified up to 10 times.

The accelerograms shown in Fig. 2 are integrated to form the ground velocity waveforms which were rotated to the transverse and radial components relative to the epicenter, and then filtered from 0.05 to $0.5 \mathrm{~Hz}$. The filtered waveforms are displayed in Fig. 4. All traces are normalized to their maximum amplitudes and aligned to the P-arrivals. The above mentioned site classes are also shown at the beginning 

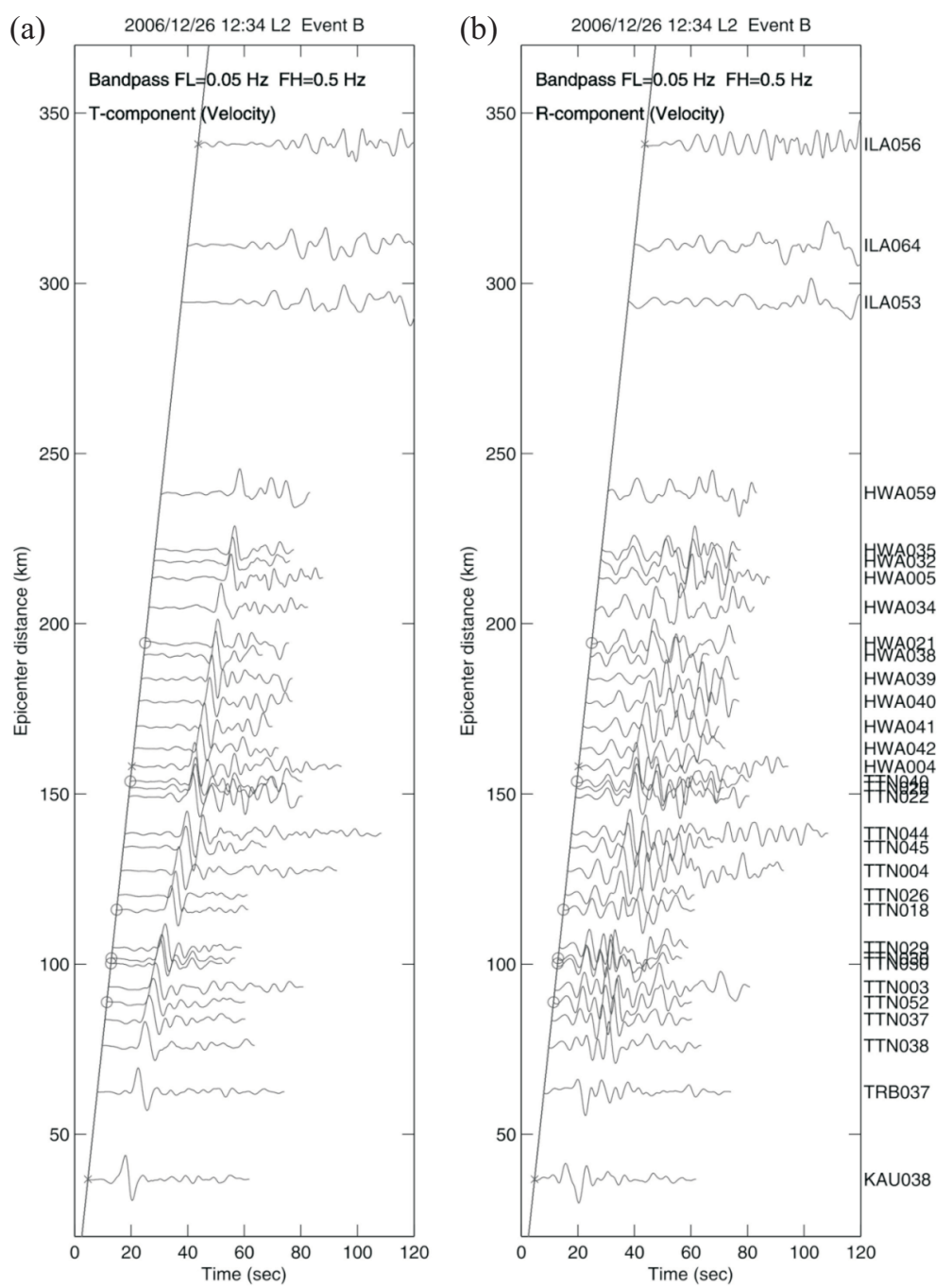

Fig. 4. (a) Transverse- and (b) radial-component ground velocity waveforms integrated from accelerograms for the B event observed at the stations along L2. Station names are shown at the right panel. All traces are filtered from 0.05 to $0.5 \mathrm{~Hz}$. Site classification defined by Lee et al. (2001) is also shown at the beginning of each trace with the same symbols as shown in Fig. 3. sediments are thin.

Like the filtered PGA, along L2 (Figs. 5c, d), the filtered PGV abruptly becomes high from 120 to $160 \mathrm{~km}$ along the LV for the A event (Fig. 5c) and from 100 to $140 \mathrm{~km}$ for the B event (Fig. 5d), and then gradually decreases with increasing distance. The anomalous area extends about $40 \mathrm{~km}$ northwards from the southern end (entrance) of the LV and is denoted by an ellipse in Fig. 1. The filtered PGV at ILA064 outside the Lanyang basin is about 5 times larger than that at ILA056 inside the basin.

\section{GROUND MOTIONS OUTSIDE AND INSIDE THE BASINS}

There are about 20 and 17 strong-motion recordings of the Pingtung offshore twin earthquakes in the Taipei basin and Lanyang basin, respectively. However, most recordings were not completely recorded by stations in the two areas due to long distances and the problem of triggering. As mentioned previously, the accelerograms are rotated to the vertical, transverse, and radial components relative to the epicenter. Since the P-waves cannot be recorded in all stations, the arrival time of the $\mathrm{S}$-waves is the main indication of arrival time. The left plots of Figs. 6a and $\mathrm{b}$ show the original three-component acceleration seismograms of the A event recorded at TAP022 and at TAP003, respectively. The P-waves are not recorded by the station TAP003. The long-period wave train after the S-waves can be seen at TAP003 (Fig. 6b). The right plots of Figs. $6 a$ and $b$ display the Fourier spectra. The predominant frequency contents are mainly in $0.8-2.0 \mathrm{~Hz}$ at TAP022 and in $0.25-1.2 \mathrm{~Hz}$ at TAP003.

The left plots of Figs. 7a and b show the rotated threecomponent acceleration seismograms of the A event recorded at ILA064 and ILA056, respectively. The accelerations after the S-waves at ILA064 show an exponential decay (Fig. 7a), while a significant long-period wave-train appears after the S-waves at ILA056 (Fig. 7b). The right plots of Figs. $7 \mathrm{a}$ and $\mathrm{b}$ display the Fourier spectra of waveforms. The predominant frequency range is $1.5-3.0 \mathrm{~Hz}$ at ILA064 and $0.28-2.0 \mathrm{~Hz}$ at ILA056.

For the B event, the results are displayed in Fig. 8 for the Taipei basin and in Fig. 9 for the Lanyang basin. The two figures clearly show that the B event also excited long-period ground motions after the S-waves inside the basins. In the Taipei basin, the ground motions are characterized by stronger low-frequency contents at TAP003 than at TAP022. Similarly, in the Lanyang basin the ground motions are charac- 

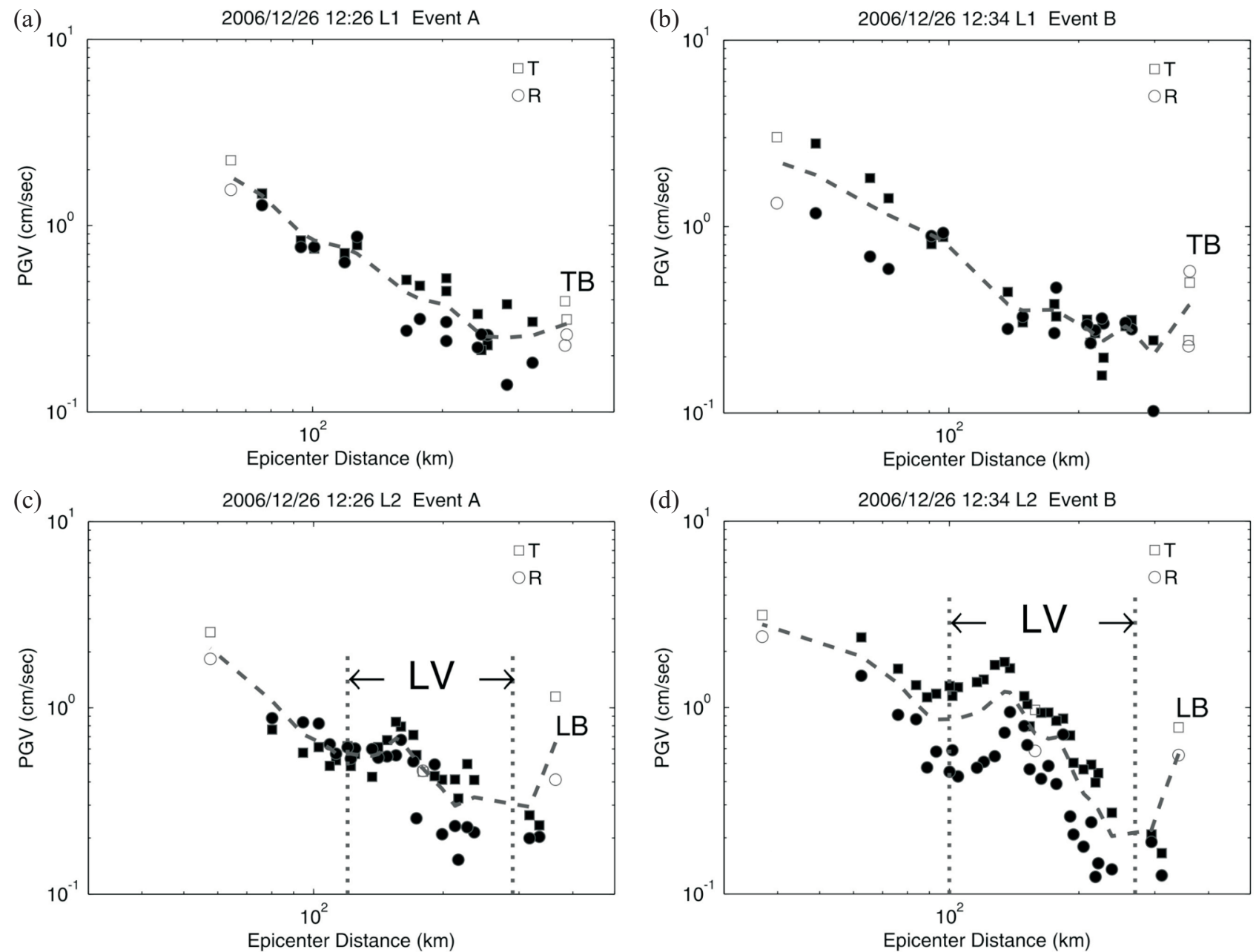

Fig. 5. The transverse and radial components of PGV filtered from 0.05 to $0.5 \mathrm{~Hz}$ as a function of distance: (a) and (b) along L1 for the A and B events and (c) and (d) along L2 for the two events. The squares and circles in each panel denote, respectively, transverse and radial components of filtered PGV. The solid and blank symbols indicate rock-type (Class-B and -C) and soil-type (Class-D and -E) sites, respectively. The dashed line denotes the smoothing curve for the filtered PGV. Note that in addition to the amplification in the Taipei basin (TB) and the Lanyang basin (LB), the filtered PGV of both two events show anomalously high values along the LV.

terized by stronger low-frequency contents at ILA056 than at ILA064.

\section{SURFACE WAVES}

In order to examine whether the above-mentioned long-period ( $>1 \mathrm{sec}$ ) ground motions after the S-waves are mainly surface waves. The accelerograms recorded were integrated to form the velocity and displacement waveforms, respectively. To retrieve an almost single frequency waveform, the displacement waveform is filtered through a narrow bandpass filter. In the followings, the displacement waveforms at the four seismic stations in use are filtered at $\mathrm{f}$ $=0.3 \mathrm{~Hz}$ through a narrow frequency band of $0.25-0.35 \mathrm{~Hz}$. Results for the B event are given in the followings. The arrival times of the $\mathrm{P}$ - and $\mathrm{S}$-waves are displayed by thin lines and the time intervals for plotting particle motions are de- noted by thick lines in Figs. 10 - 13.

The acceleration, velocity, and displacement waveforms generated by the B event recorded at TAP022 are displayed in Fig. 10a. Clearly, the ground motions consist of significant late-arriving, long-period motions. Fig. 10b shows the filtered three-component waveforms at TAP022 from the displacement waveforms in Fig. 10a. On the basis of the T-component, there are two wave-packets: the first one from 65 to $82 \mathrm{sec}$ and the second one after $88 \mathrm{sec}$. But, only associated with the first wave-packet there are wave-packets in the $\mathrm{V}$ - and R-components. The wave-packet of the T-component comes earlier than those of the V-and R-components. Meanwhile, the R-component wave-packet comes earlier than the V-component. These phenomena may suggest the existence of Love waves along the T-component and Rayleigh waves along the $\mathrm{V}$ - and $\mathrm{R}$-components in this time interval at TAP022, and some multi-pathing effect cannot be 

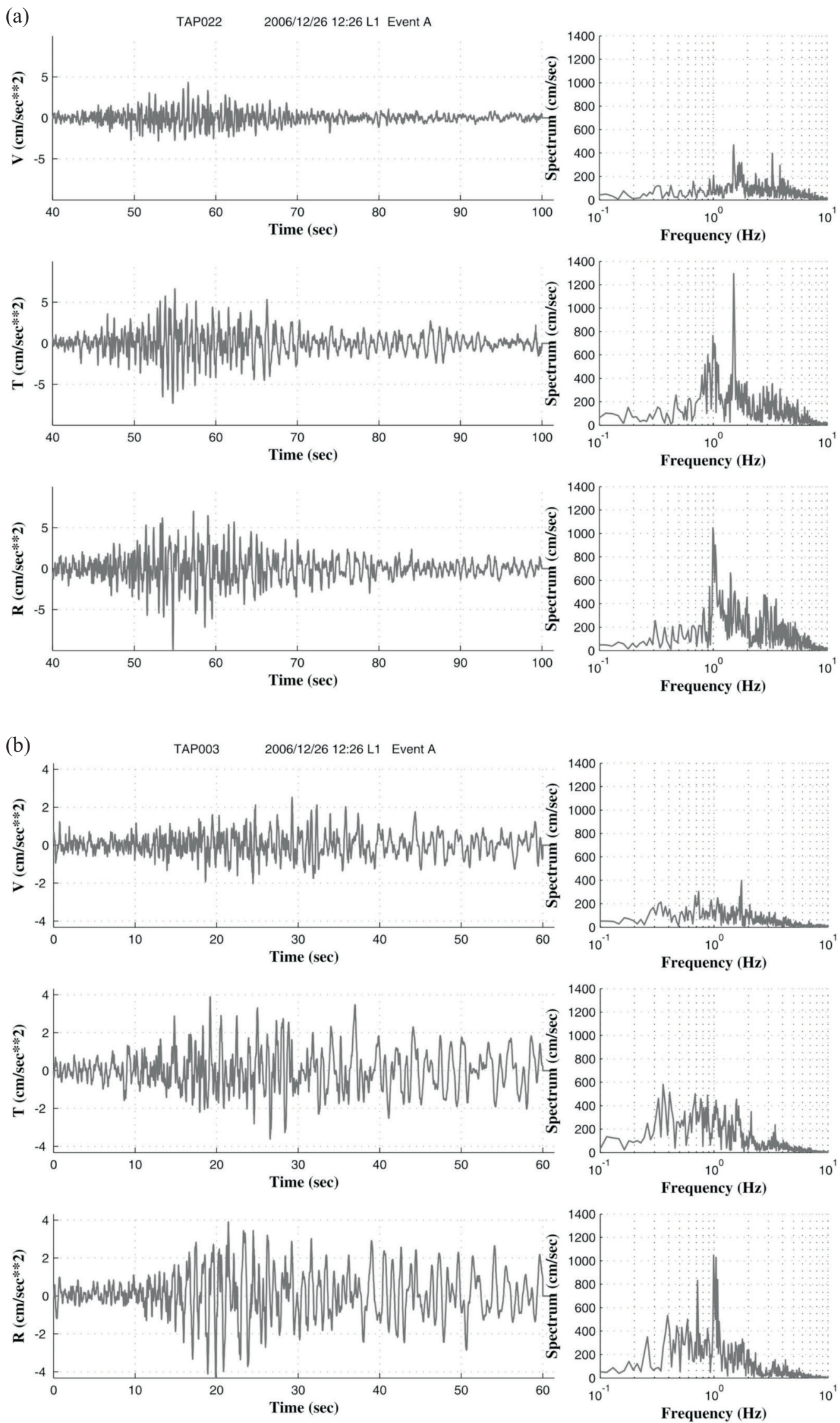

Fig. 6. The rotated three-component acceleration seismograms of the A event recorded at (a) TAP022 and (b) TAP003. The individual Fourier amplitude spectra are shown in the right panels. 

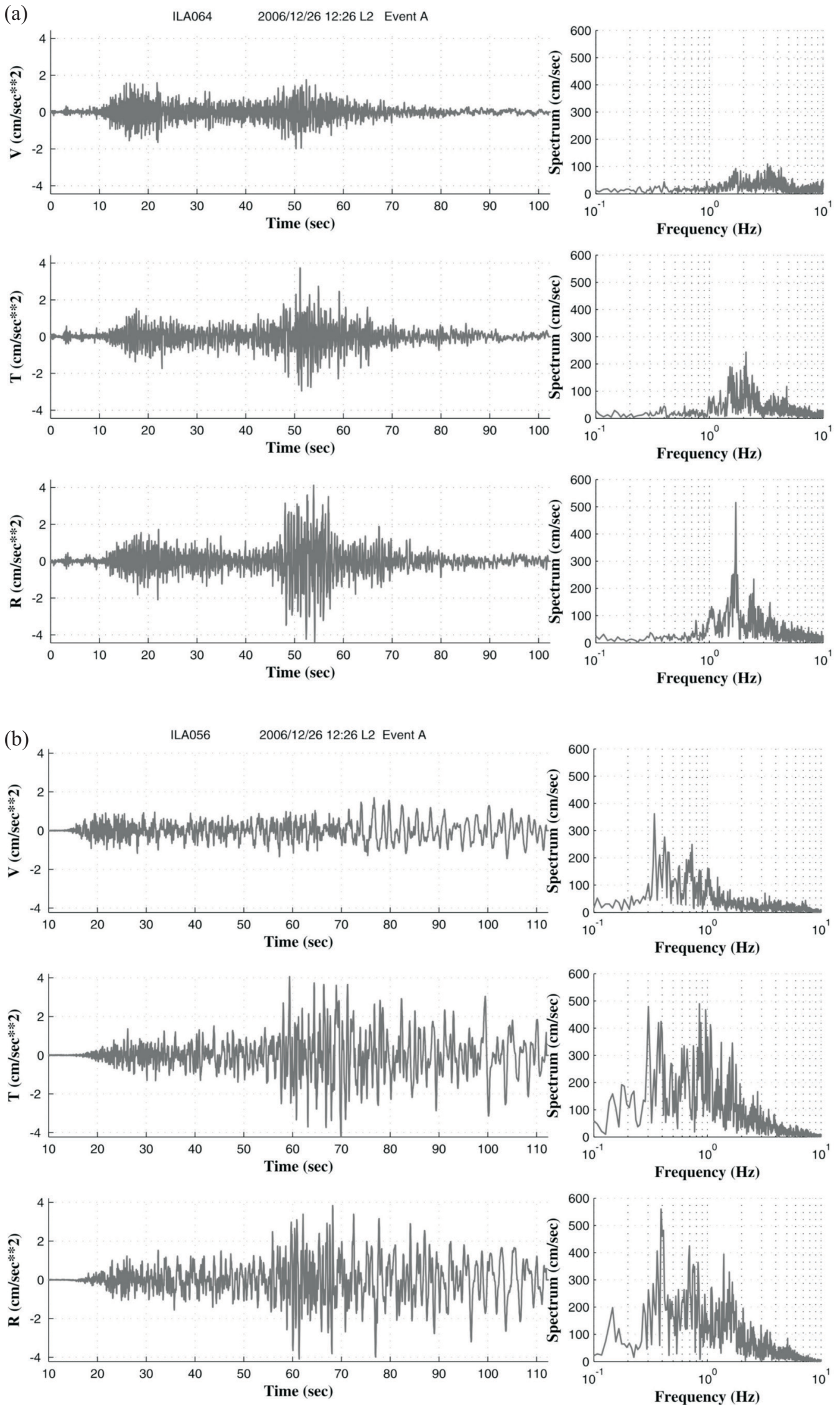

Fig. 7. The rotated three-component acceleration seismograms of the A event recorded at (a) ILA064 and (b) ILA056. The individual Fourier amplitude spectra are shown in the right panels. 

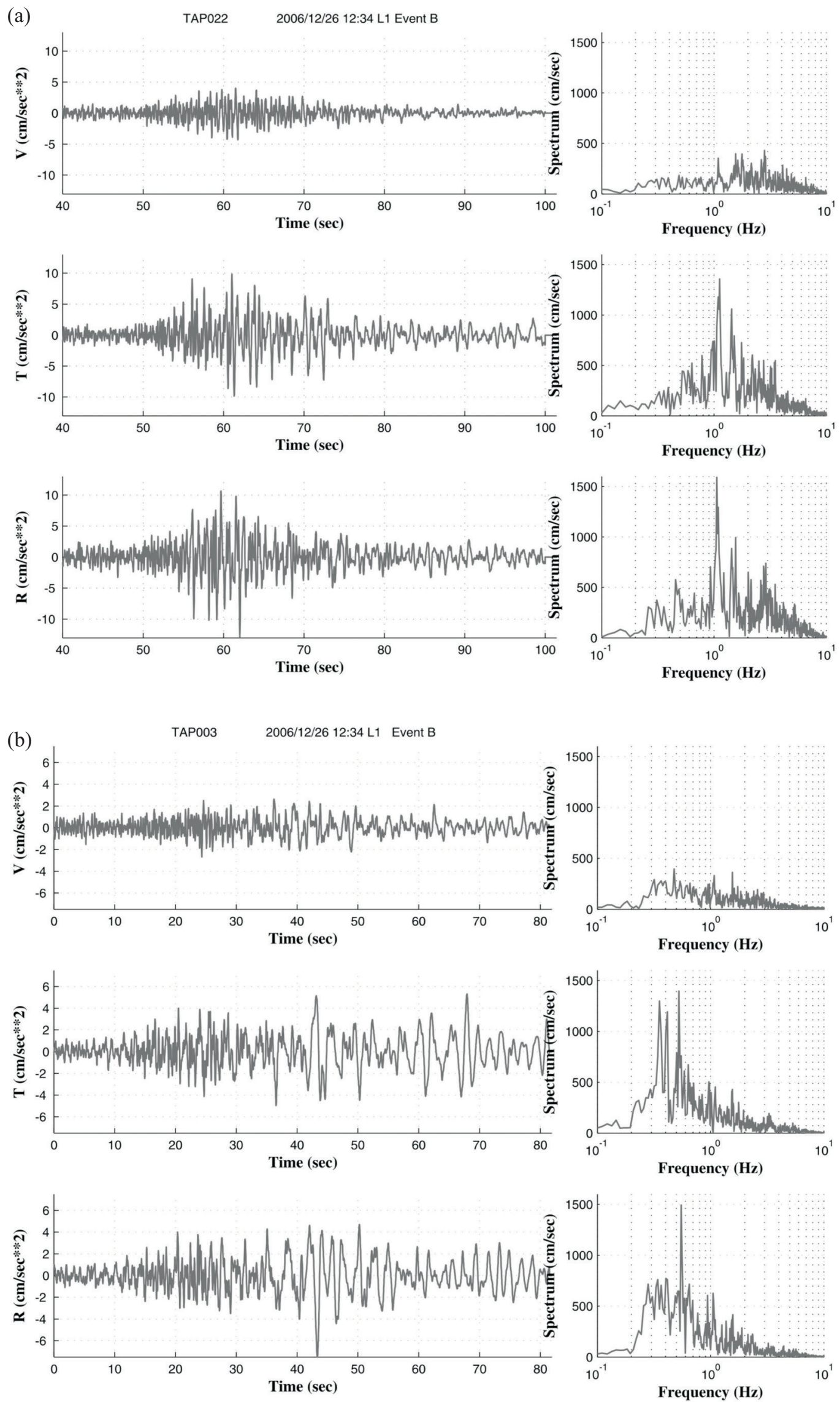

Fig. 8. The rotated three-component acceleration seismograms of the B event recorded at (a) TAP022 and (b) TAP003. The individual Fourier amplitude spectra are shown in the right panels. 

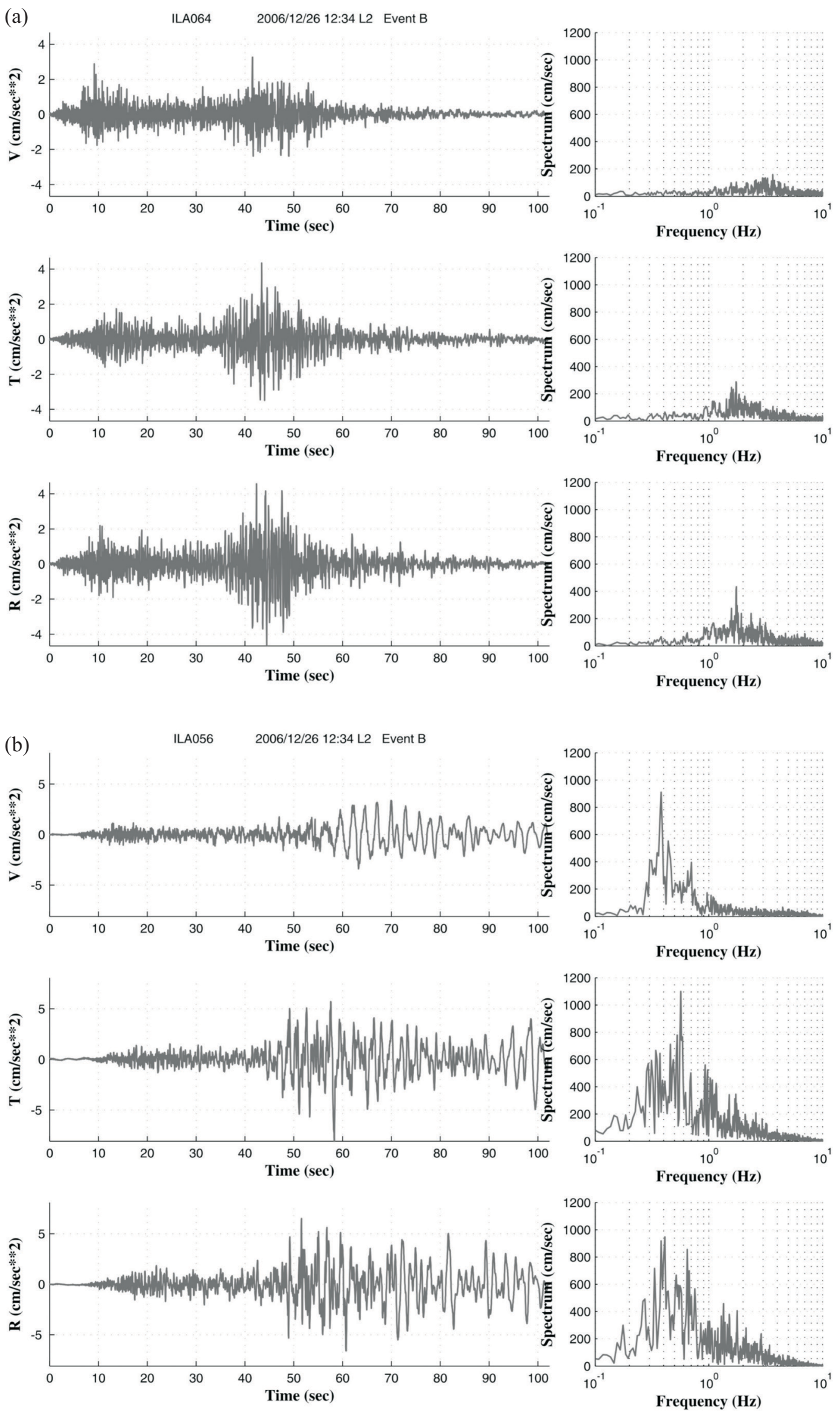

Fig. 9. The rotated three-component acceleration seismograms of the B event recorded at (a) ILA064 and (b) ILA056. The individual Fourier amplitude spectra are shown in the right panels. 
(a)
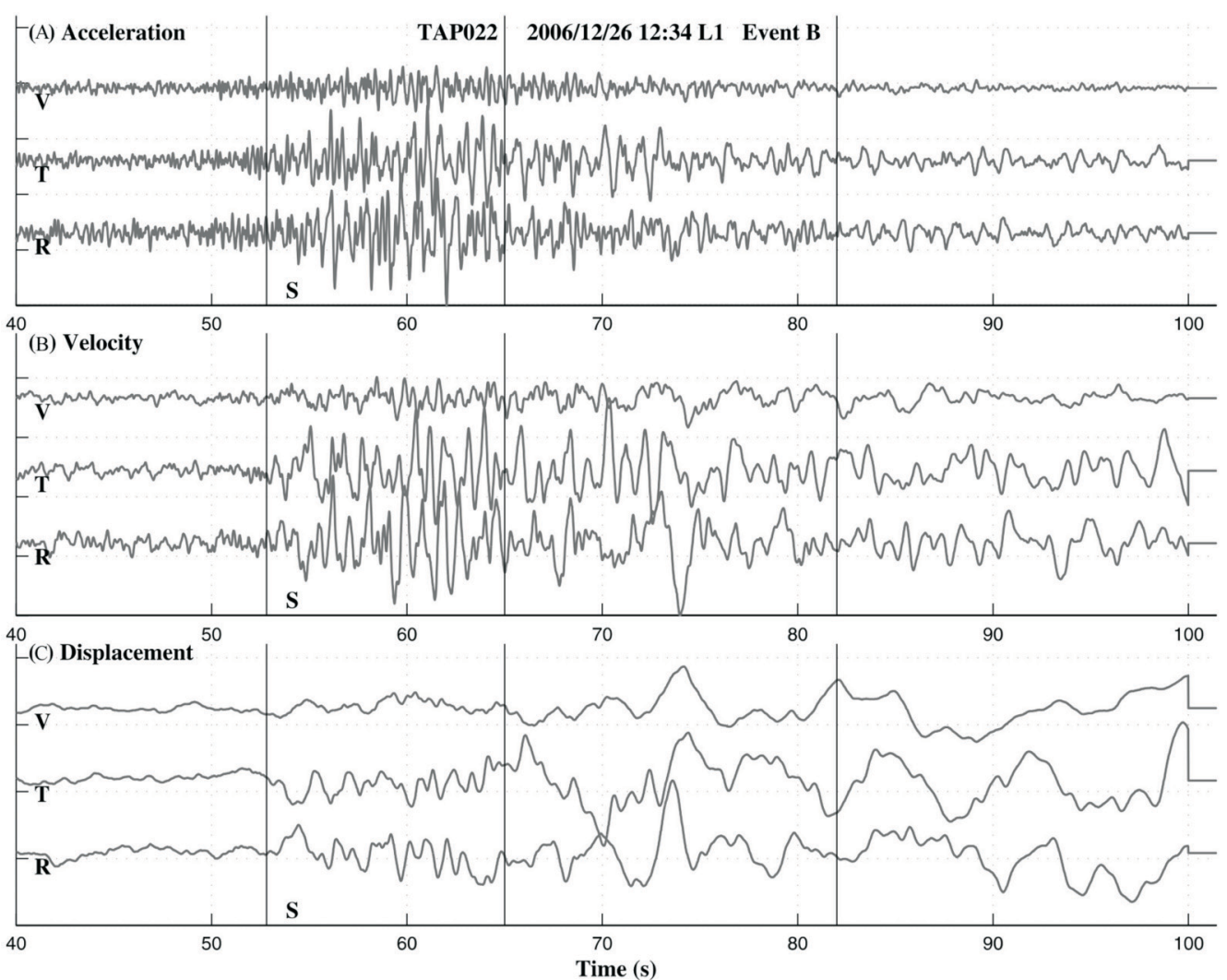

(b)

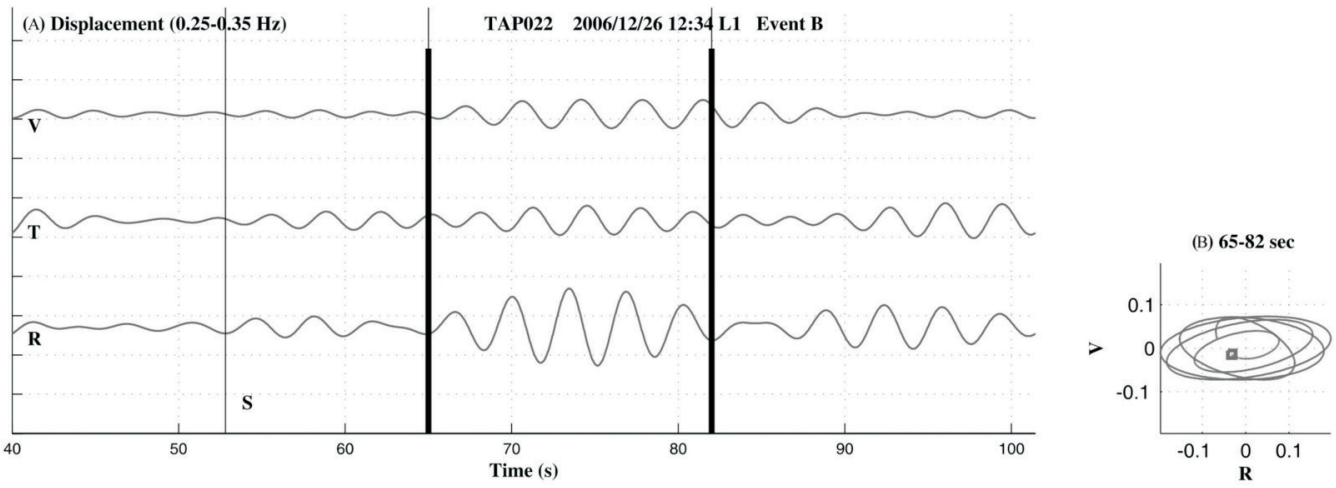

Fig. 10. (a) The rotated three-component accelerograms, velocity waveforms, and displacement waveforms of the B event recorded at TAP022; (b) The filtered displacement waveforms in the frequency band of $0.25-0.35 \mathrm{~Hz}$ and the particle motions in the time interval of $65-82 \mathrm{sec}$. Square refers to the start of particle motion.

ruled out. It is noted that the amplitudes are smaller for the V-component than the R-component. To examine the possible existence of Rayleigh waves, the trajectory of particle motions of displacements composed by the V- and R-component in this time interval is made and depicted in Fig. 10b. Obviously, the retrograde particle motions in the time interval of 65 - $82 \mathrm{sec}$ display elliptical polarization in the wave propagation plane, thus confirming the existence of Rayleigh waves at least in this time interval. After $88 \mathrm{sec}$, there is a wave-packet in the $\mathrm{T}$ - and $\mathrm{R}$-components traces. However, there is no related wave-packet in the V-component. This wave-packet contains little energy from Rayleigh waves.

The acceleration, velocity, and displacement waveforms generated by the B event recorded at TAP003 are displayed in Fig. 11a. Clearly the ground motions consist of significant late-arriving, long-period motions. The filtered waveforms at $\mathrm{f}=0.3 \mathrm{~Hz}$ are displayed in Fig. $11 \mathrm{~b}$. For the T-component, there are, at least, three wave-packets, and the second one is stronger than the first. For the $\mathrm{V}$ - and R-component, there is mainly a strong wave-packet in the time interval of $32-48 \mathrm{sec}$ and a weak wave-packet after $58 \mathrm{sec}$. The strong wavepackets are associated with and come slightly later than the 
(a)
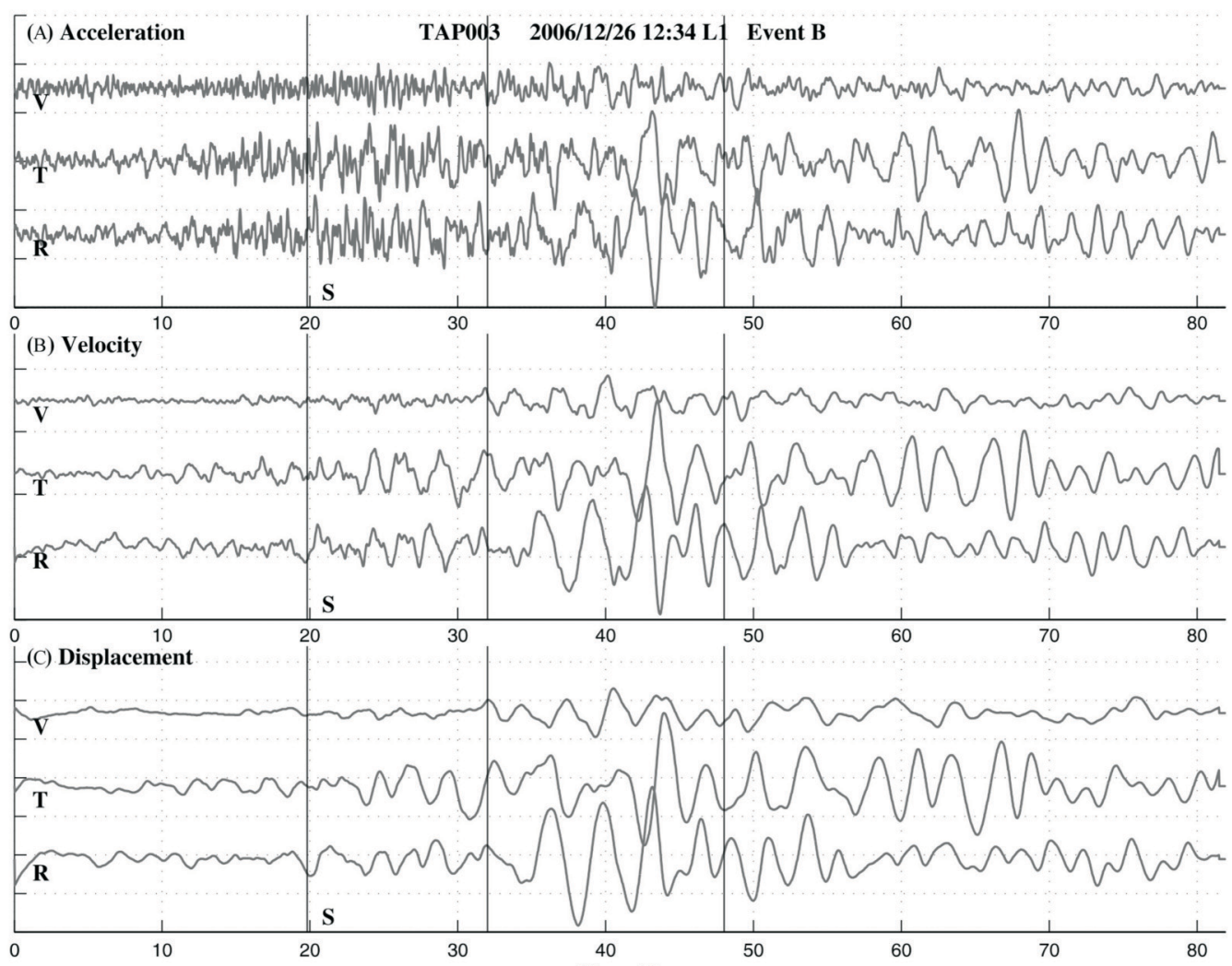

(b)

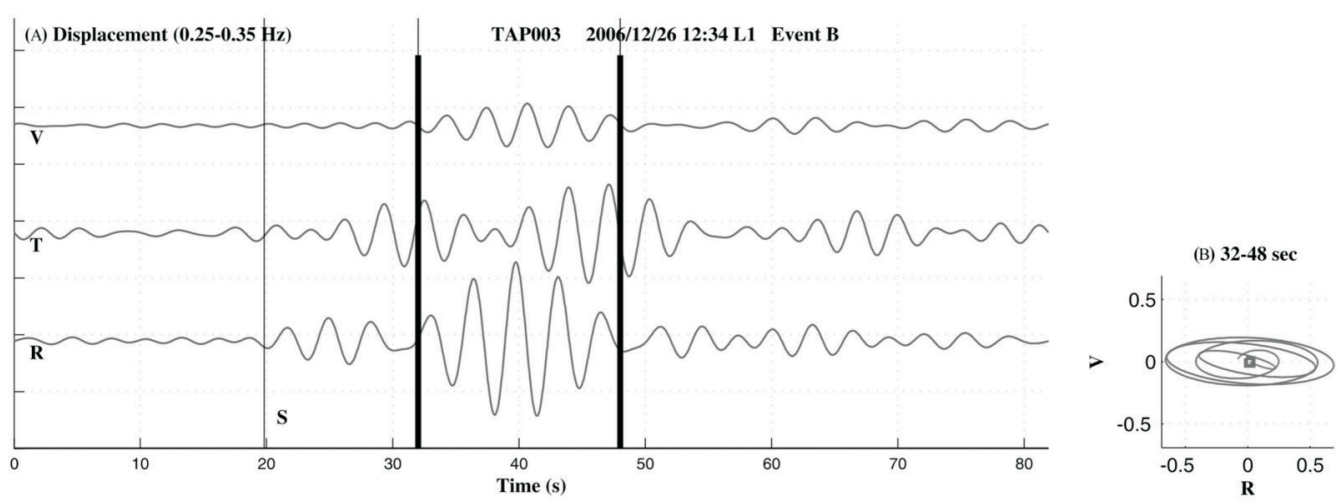

Fig. 11. (a) The rotated three-component accelerograms, velocity waveforms, and displacement waveforms of the B event recorded at TAP003; (b) The filtered displacement waveforms in the frequency band of $0.25-0.35 \mathrm{~Hz}$ and the particle motions in the time interval of $32-48 \mathrm{sec}$. Square refers to the start of particle motion.

wave-packet of the T-component. These phenomena might suggest the existence of Love waves along the T-component and Rayleigh waves along the $\mathrm{V}$ - and R-components at TAP003. The amplitudes are in general larger for the Rcomponent than for the $\mathrm{V}$-component. The particle motions of the strong wave-packets are also displayed in Fig. 11b. Obviously, the retrograde particle motions show elliptical polarization in the wave propagation plane, thus confirming the existence of Rayleigh waves. There are T-component wave-packets associated with but appear earlier than the above-mentioned V-and R-component wave-packets. This suggests the existence of Love waves.

Similarly, surface waves are also examined at two seismic stations in the Lanyang basin. Fig. 12a shows the acceleration, velocity, and displacement waveforms generated by the B event recorded at ILA064. Obviously, the ground motions at this station include significant late-arriving, long-period motions after $40 \mathrm{sec}$. The displacement waveforms filtered at $\mathrm{f}=0.3 \mathrm{~Hz}$ are displayed in Fig. $12 \mathrm{~b}$. The filtered waveforms are quite complicated, and there are several wave-packets. Nevertheless, during 54 - $71 \mathrm{sec}$ there is a nice wave-packet in each waveform. The wave-packet of 
(a)
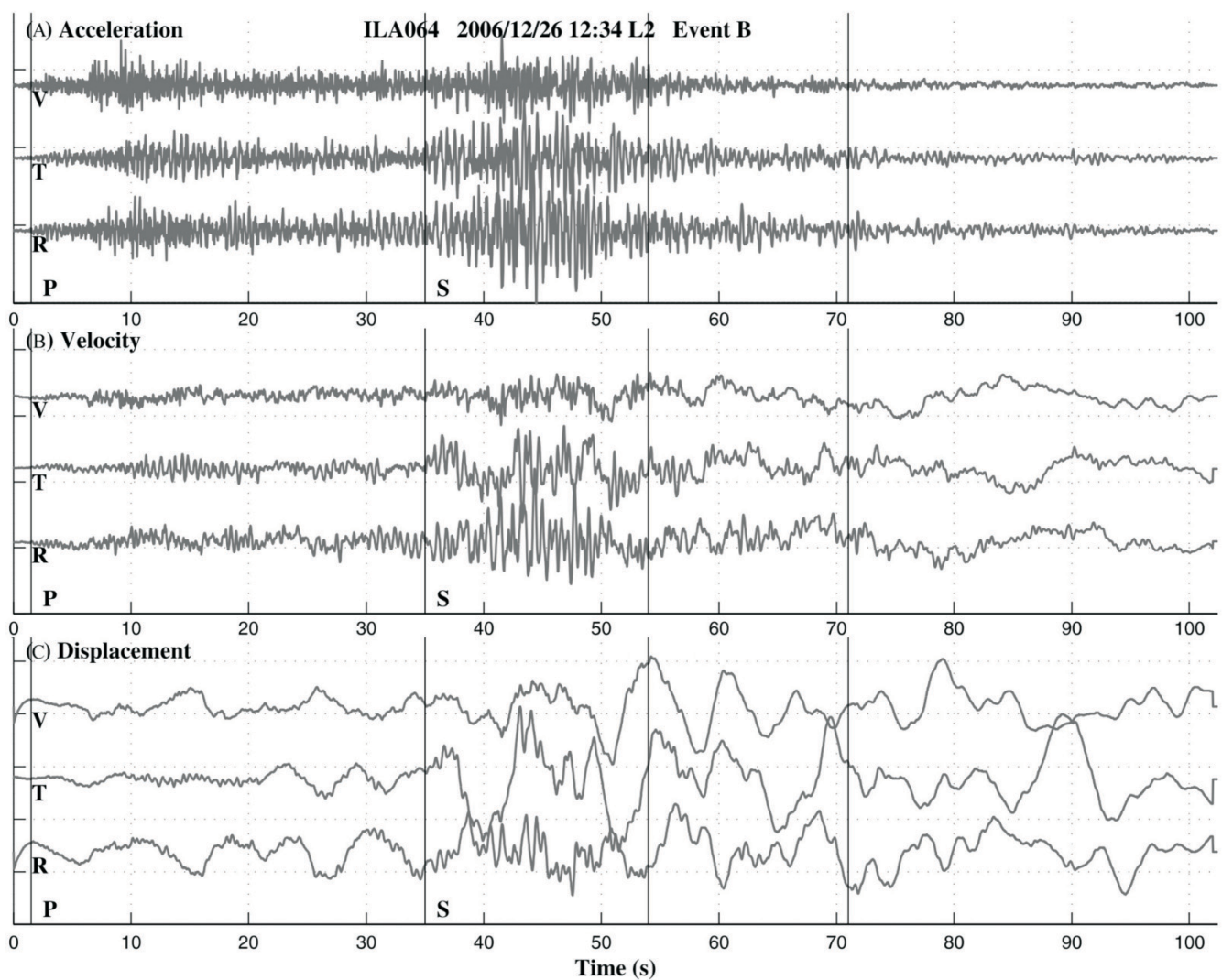

(b)

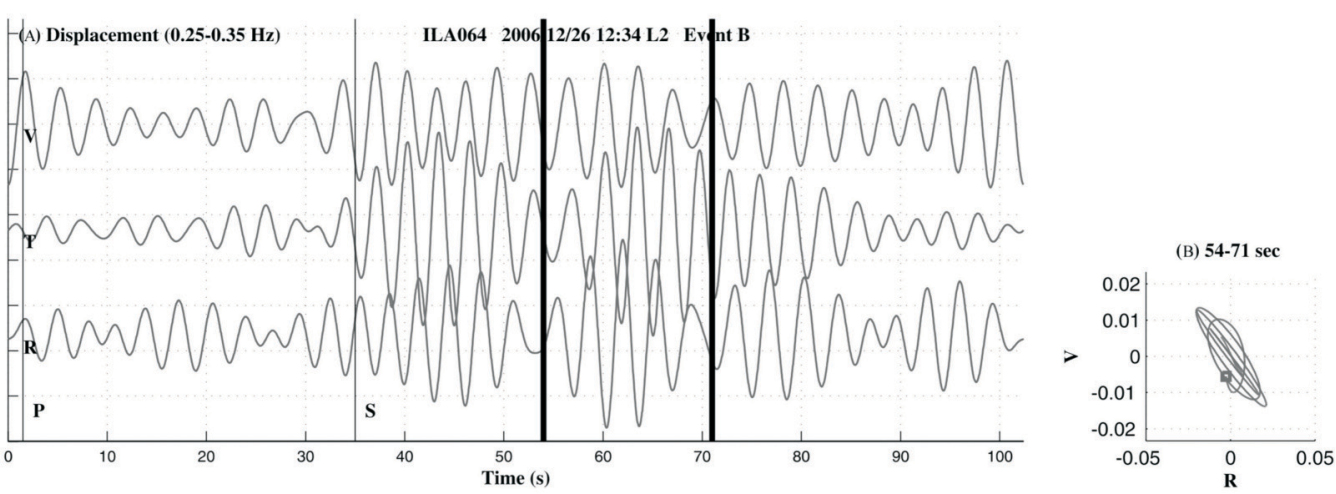

Fig. 12. (a) The rotated three-component accelerograms, velocity waveforms, and displacement waveforms of the B event recorded at ILA064; (b) The filtered displacement waveforms in the frequency band of $0.25-0.35 \mathrm{~Hz}$ and the particle motions in the time interval of $54-71 \mathrm{sec}$. Square refers to the start of particle motion.

the T-component comes earlier than those of the V- and R-components. Meanwhile, the R-component wave-packet comes earlier than the V-component one. These phenomena might suggest the existence of Love waves along the Tcomponent and Rayleigh waves along the V- and R-components in this time interval at ILA064. The amplitudes are larger for the R-component than for the V-component. To examine the possible existence of Rayleigh waves, the trajectory of particle motions composed of the V- and R-component wave- packets in this time interval is also shown in Fig. 12b. These retrograde particle motions clearly imply the
Rayleigh-type elliptical polarization in the wave propagation plane.

Figure 13a shows the acceleration, velocity, and displacement waveforms generated by the B event recorded at ILA056. Obviously, the ground motions at this station include significant late-arriving, long-period motions after $50 \mathrm{sec}$. The displacement waveforms filtered at $\mathrm{f}=0.3 \mathrm{~Hz}$ are displayed in Fig. 13b. The filtered waveforms are quite complicated, and there are several wave-packets. During 61 - $74 \mathrm{sec}$, there are wave-packets in the three waveforms. The wave-packet of the T-component comes earlier than those of 
(a)
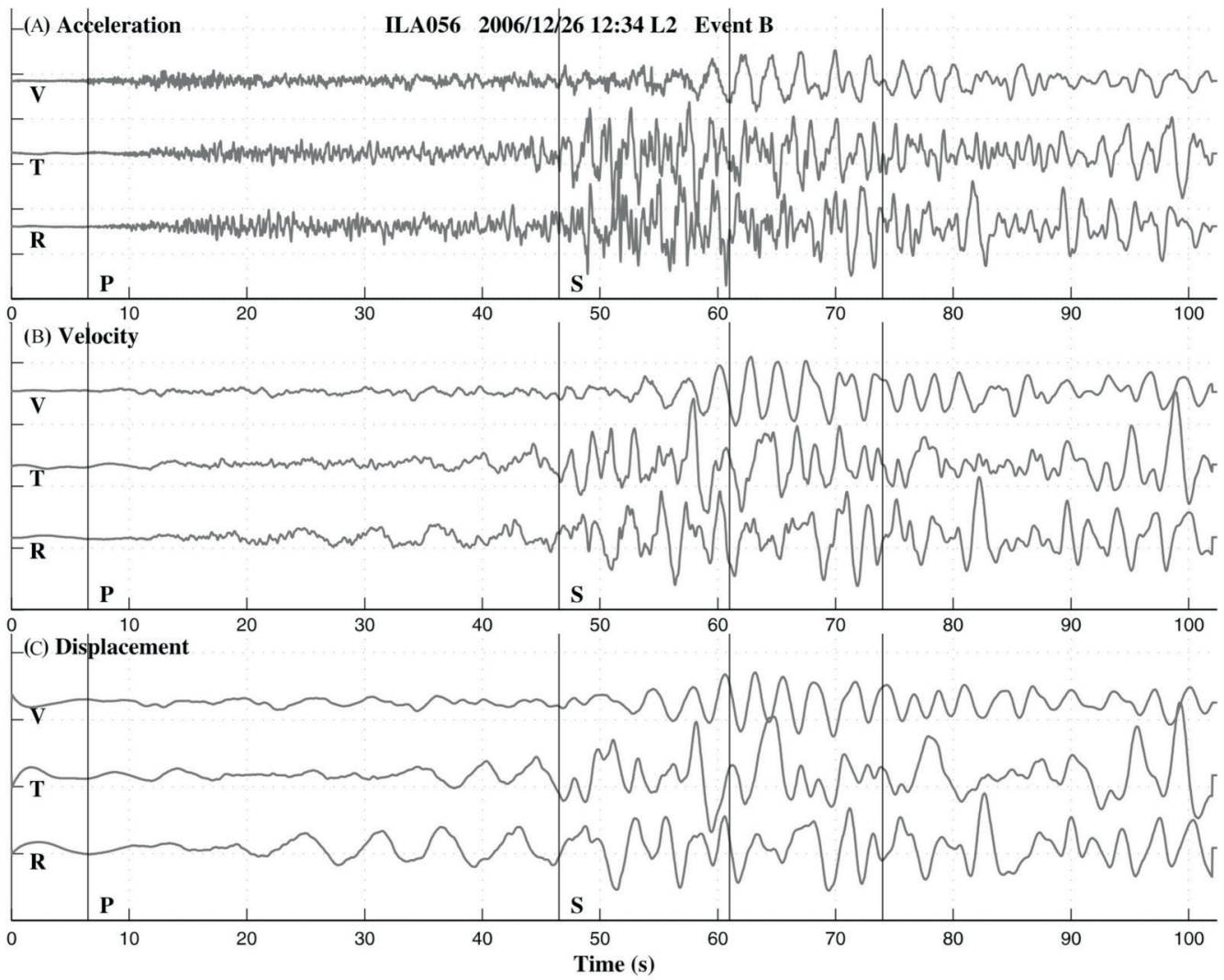

(b)

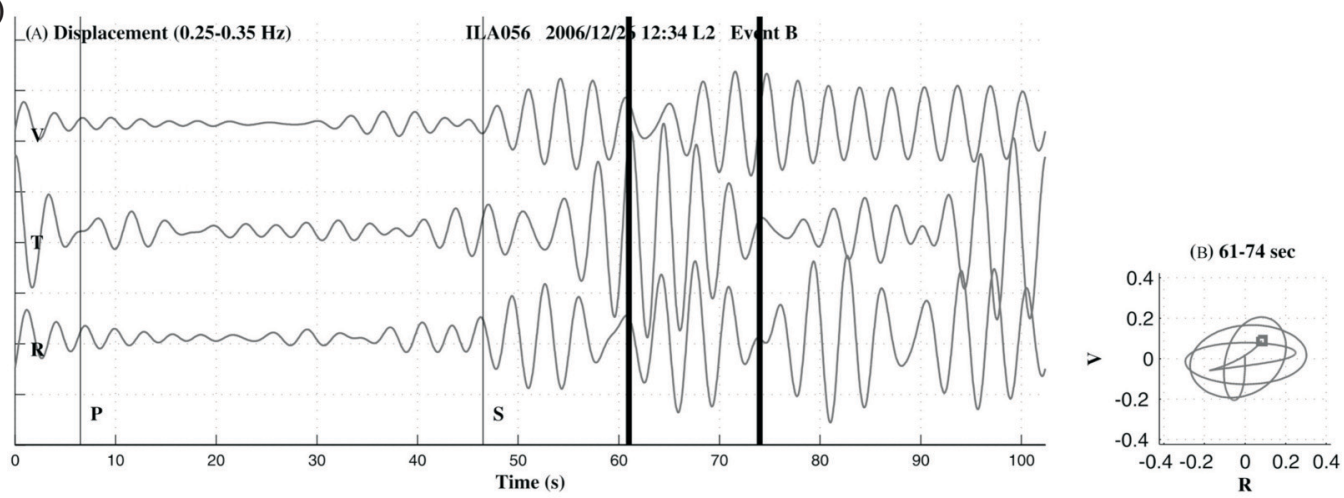

Fig. 13. (a) The rotated three-component accelerograms, velocity waveforms, and displacement waveforms of the B event recorded at ILA056; (b) The filtered displacement waveforms in the frequency band of $0.25-0.35 \mathrm{~Hz}$ and the particle motions in the time interval of $61-74 \mathrm{sec}$. Square refers to the start of particle motion.

the V-and R-components. Meanwhile, the R-component wave-packet comes earlier than the V-component one. These phenomena might suggest the existence of Love waves along the T-component and Rayleigh waves along the $\mathrm{V}$ - and R-components in the time interval at ILA056. The amplitudes are larger for the R-component than for the V-component. To examine the possible existence of Rayleigh waves, the trajectory of particle motions composed of the V- and R-component wave-packets in the time interval is also shown in Fig. 13b. These retrograde particle motions clearly imply elliptical polarization in the wave propagation plane, thus confirming Rayleigh wave motions.

\section{DISCUSSIONS}

As shown in Fig. 3, most of the horizontal PGA values from the two events recorded at the stations along L1 and L2 lie within one standard deviation of the mean attenuation curve inferred by Lin and Lee (2008). The observed longperiod PGA in the range $0.05-0.5 \mathrm{~Hz}$ are about 2 to 10 times larger inside than outside the Taipei basin and Lanyang basin. The long-period PGA and PGV along L1 somewhat de- 
crease with increasing distance for both events (see Figs. 3a, b, 5a, b); anomalously high PGA and PGV are observed along L2 in the LV. It is noted that most rock sites along L1 are Class-B, while those along L2 are Class-C (Figs. 2, 4). Hence, the anomalously high long-period PGA and PGV along L2 in the LV could be caused by the thick layers of very dense soil and soft fault-zone rocks (Class-C). In addition, the difference in the long-period PGA and PGV between L1 and L2 might also be caused by different velocities of the subsurface structures underneath the two linear profiles.

Although the epicenters of the twin events are about $30 \mathrm{~km}$ apart, their long-period PGA and PGV abruptly increase with distance in an area extending about $40 \mathrm{~km}$ northwards from the southern end of the LV. This area is shown by an ellipse in Fig. 1. High-resolution 3D tomographic results of the collision suture zone in eastern Taiwan (Kim et al. 2005 , 2006) reveal that the subsurface low-velocity layers are thicker in the southern part of the LV than in the north. Such thick subsurface low-velocity layers could play an important role in amplification of long-period ground motions. The above-mentioned anomalous area is most likely to be associated with the thick subsurface low-velocity layers. In 2003, an $M_{w} 6.8$ earthquake occurred in this area (Huang et al. 2008). Although that event did not kill people, it resulted in remarkable surface ruptures and damaged some buildings. It is assumed that site amplifications of long-period ground motions have to be taken into account.

For the long-period ground motions (Figs. 2b, 4), the $\mathrm{S}$-waves are the most prominent phase at each station. The long-period wave train with large amplitudes after the Swaves can be observed only at the stations with distances longer than $230 \mathrm{~km}$. The surface wave which might be generated in the course of seismic-wave propagation will result in the well-developed long-period ground motions in the basins.

Figures 6 - 9 show remarkable differences in the ground motions (including waveforms and Fourier spectra) between TAP022 and TAP003 in the Taipei basin and between ILA064 and ILA056 in the Lanyang basin. The difference in the high-frequency regime is interesting, but out of the scope of this study, and only the low-frequency ( $\mathrm{f}<1 \mathrm{~Hz}$ ) or long-period regime of ground motions is discussed. The ground motions are specified with stronger low-frequency contents at TAP003 and ILA056 than at TAP022 and ILA064. Such a difference is remarkable only in the $\mathrm{V}$ - and R-components in the Taipei basin, but in all the three components in the Lanyang basin. Figures 10 and 11 show that the amplitudes of Rayleigh wave-packet are larger at TAP003 than at TAP022. Similarly, Figs. 12 and 13 also show that the amplitudes of Rayleigh wavepacket are larger at ILA056 than at ILA064. TAP003 is located at the western side, with thick sediments, of the Taipei basin, while TAP022 at the eastern margin, with thin sediments, of the basin. ILA060 is situated inside the Lanyang basin with thick sediments, while ILA064 outside and at the mountain area with very thin sediments. The seismograms recorded at the stations without sediments mainly reflect the source and path effects and only slightly affected by the site effect in the very high frequency regime, while those at the station with sediments are influenced by all three effects. The site effect will play a significant role on the ground motions with $\mathrm{f}>0.01 \mathrm{~Hz}$ (cf. Huang et al. 2007). Longer waves will sense deeper structures. There are thicker sediments beneath TAP003 and ILA056 than beneath TAP022 and ILA064. Hence, the low-frequency signals at TAP003 and ILA056 could be stronger than those at TAP022 and ILA064. Of course, the reasons why in the low-frequency regime the signals in the V-component are only slightly higher at TAP003 than at TAP022 are still open questions.

The waveforms and particle motions at $\mathrm{f}=0.3 \mathrm{~Hz}$ shown in Figs. 10 - 13 suggest the existence of surface waves. It is noted that the trajectory of particle motions of Rayleigh waves is not rightly vertical, yet with a large inclination angle. The trajectory of particle motions of Rayleigh waves must be rightly vertical, when the waves propagate in a laterally homogeneous layered model. From numerical simulations of Rayleigh waves propagating along a laterally inhomogeneous half-space model, Wang and Wu (1989) found that the trajectory can inclined in the vicinity of change of velocities. Koketsu et al. (2005) also found that the trajectory is inclined. Hence the inclined trajectory observed in the Taipei basin and Lanyang basin is reasonable and indicates lateral inhomogeneity of the subsurface velocity model.

Figures 10 - 13 also show that the waveforms are more complicated in the Lanyang basin than in the Taipei basin. The waves recorded in the Taipei basin mainly propagate along the Western Costal Plain and Western Foothill, while those recorded in the Lanyang basin almost along the Central Range. The degree of complexity of sub-surface velocity structures is higher in the Central range than in the Western Costal Plain and Western Foothill (Rau and Wu 1995; Ma et al. 1996; Kim et al. 2005). This might be the main reason causing the difference in the complexity of waveforms between the Taipei basin and the Lanyang basin.

\section{CONCLUSIONS}

The strong-motion seismograms of the 26 December 2006 Pingtung offshore twin earthquakes in southern Taiwan provide valuable information to study the characteristics of ground motions attenuation along two linear profiles: L1 from station KAU038 to the Taipei basin across the western side of the Central Range, and L2 from station TRB037 through the LV to the Lanyang basin. The horizontal PGA from the two events recorded along L1 and L2 lie within one standard deviation of the mean attenuation curve inferred by 
Lin and Lee (2008). The anomalously high long-period PGA and PGV along the LV may be caused by the thick layers of very dense soil and soft fault-zone rocks (Class-C). The anomalous area in the southern end of LV shown in Fig. 1 is most likely to be associated with the thick low-velocity subsurface structures.

The twin earthquakes excited long-period ( $>1 \mathrm{sec})$ ground motions after the $\mathrm{S}$-waves in the basins, about $350 \mathrm{~km}$ away from the source region. The degree of complexity of waveforms is higher in the Lanyang basin than in the Taipei basin. This might be due to a fact that the subsurface velocity structures along the ray-path from the epicenters to the former is more complicated that those along the ray-path from the epicenters to the latter. The ground motions in the Taipei basin are characterized by stronger low-frequency $(<1 \mathrm{~Hz})$ signals at the station with thick sediments inside the basin than at the station with thin sediments at the margin of the basin. Similarly, the ground motions in the Lanyang basin are specified by stronger low-frequency $(<1 \mathrm{~Hz})$ signals at the station inside the basin than at that outside the basin.

The waveforms are filtered at a frequency of $0.3 \mathrm{~Hz}$ through a narrow window of $0.25-0.35 \mathrm{~Hz}$. Filtered waveforms clearly display the existence of wave-packets which might be associated Love waves in the T-component and Rayleigh waves in the V-and R-components. In both basins, the particle motions of the predominant wave-packet of $\mathrm{V}$ and R-component filtered waveforms retrograde. This shows elliptical polarization in the wave propagation plane, confirming the Rayleigh waves.

Acknowledgements The authors would like to express their thanks to Prof. William H. K. Lee and an anonymous reviewer for constructive comments. The Seismological Observation Center of Central Weather Bureau provided invaluable strong motion data. This work was sponsored by Academia Sinica under Grant no. AS-94-TP-A08 and the National Science Council, ROC, under grant NSC 952119-M-001-053, with TEC Contribution Number 00041.

\section{REFERENCES}

Chang, H. C., C. W. Lin, M. M. Chen, and S. T. Lu, 1998: An Introduction to the Active Faults of Taiwan, Explanatory Text of the Active Fault Map of Taiwan SCALE $1: 55000$, Central Geol. Surv., MOEA, ROC, 103 pp. (in Chinese)

Chang, T. M., K. L. Wen, T. Furumura, and H. J. Chiang, 2002: Surface wave excitation in the western coastal plain of Taiwan during the 1999 Chi-Chi earthquake. J. Chin. Inst. Eng., 25, 461-467.

Chen, K. C., 2003: Strong ground motion and damage in the Taipei basin from the Moho reflected seismic waves during the March 31, 2002, Hualien, Taiwan earthquake. Geophys. Res. Lett., 30, doi: 10.1029/2003GL017193.

Chen, K. C. and J. H. Wang, 1988: A study on aftershocks and focal mechanisms of two 1986 earthquakes in Hualien, Taiwan. Proc. Geol. Soc. China, 31, 65-72.

Chen, K. C., B. S. Huang, and J. H. Wang, 2002: Conjugate thrust faulting associated with the 1999 Chi-Chi, Taiwan earthquake sequence. Geophys. Res. Lett., 29, 1277, doi: 10.1029/2001GL014250.

Cheng, S. N., Y. T. Yeh, M. T. Hsu, and T. C. Shin, 1999: Photo album of ten disastrous earthquakes in Taiwan, Central Weather Bureau Special Publication, 290 pp. (in Chinese)

Chiang, S. C., 1976: A seismic refraction prospecting of the Ilan plain. Mining Tech., 14, 215-221. (in Chinese)

Chung, J. K. and Y. T. Yeh, 1997: Shallow crustal structure from short-period Rayleigh-Wave dispersion data in southwestern Taiwan. Bull. Seismol. Soc. Am., 87, 370-382.

Frankel, A. D., S. Hough, P. Friberg, and R. Busby, 1991: Observations of Loma Prieta aftershocks from a dense seismic array in Sunnyvale, California. Bull. Seismol. Soc. Am., 81, 1900-1922.

Frankel, A. D., D. Carver, E. Cranswick, T. Bice, R. Sell, and S. Hanson, 2001: Observations of basin ground motions from a dense seismic array in San Jose, California. Bull. Seismol. Soc. Am., 91, 1-12.

Furumura, T. and T. Hayakawa, 2007: Anomalous propagation of long-period ground motions recorded in Tokyo during the 23 October $2004 \mathrm{M}_{\mathrm{w}}$ 6.6 Niigata-ken Chuetsu, Japan, earthquake. Bull. Seismol. Soc. Am., 97, 863-880.

Hsu, S. K., J. Kuo, C. L. Lo, C. H. Tsai, W. B. Doo, C. Y. Ku, and J. C. Sibuet, 2008: Turbidity currents, submarine landslides and the 2006 Pingtung earthquake off SW Taiwan. Terr. Atmos. Ocean. Sci., 19, 767-772, doi: 10.3319/TAO. 2008.19.6.767(PT).

Huang, B. S., W. G. Huang, Y. L. Huang, L. C. Kuo, K. C. Chen, and J. Angelier, 2008: Complex fault rupture during the 2003 Chengkung, Taiwan earthquake sequence from dense seismic array and GPS observations. Tectonophysics, in press.

Huang, M. W., J. H. Wang, K. F. Ma, C. Y. Wang, J. H. Hung, and K. L. Wen, 2007: Frequency-dependent site amplifications with $\mathrm{f} \geq 0.01 \mathrm{~Hz}$ evaluated from the velocity and density models in Central Taiwan. Bull. Seismol. Soc. Am., 97, 624-637.

Huang, R. D., G. K. Yu, W. Y. Chang, and J. P. Chang, 2003: Lateral variations of shallow shear-velocity structure in southwestern Taiwan inferred from short-period Rayleigh waves. Earth Planets Space, 55, 349-354.

Kim, K. H., J. M. Chiu, J. Pujol, K. C. Chen, B. S. Huang, Y. H. Yeh, and P. Shen, 2005: Three-dimensional VP and VS structural models associated with the active subduction and collision tectonics in the Taiwan region. Geophys. J. Int., 162, 204-220.

Kim, K. H., J. M. Chiu, J. Pujol, and K. C. Chen, 2006: Polarity reversal of active plate boundary and elevated oceanic upper mantle beneath the collision suture in central eastern Taiwan. Bull. Seismol. Soc. Am., 96, 796-806.

Koketsu, K., K. Hatayama, T. Furumura, Y. Ikegami, and S. Akiyama, 2005: Damaging long-period ground motions 
from the $2003 \mathrm{M}_{\mathrm{w}} 8.3$ Tokachioki, Japan, earthquake. Seismol. Res. Lett., 76, 67-73.

Lee, C. T., C. T. Cheng, C. W. Liao, and Y. B. Tsai, 2001: Site classification of Taiwan free-field strong-motion stations. Bull. Seismol. Soc. Am., 91, 1283-1297.

Lin, C. C., 2001, Geology environment of Taipei metropolis, Symp. on Geol. Hazards of Taipei Metropolis, 1-19. (in Chinese)

Lin, P. S. and C. T. Lee, 2008: Ground-motion attenuation relationships for subduction-zone earthquakes in northeastern Taiwan. Bull. Seismol. Soc. Am., 98, 220-240.

Liu, K. S. and Y. B. Tsai, 2007: Intensity Amplification of Seismic Excitation for 28 Buildings during the 1999 ChiChi Earthquake, Taiwan. J. Architect., 61, 151-173. (in Chinese)

Ma, K. F., J. H. Wang, and D. Zhao, 1996: Three-dimensional seismic velocity structure of the crust and uppermost mantle beneath Taiwan. J. Phys. Earth., 44, 85-105.

Miyake, H. and K. Koketsu, 2005: Long-period ground motions from a large offshore earthquake: The case of the 2004 off the Kii peninsula earthquake, Japan. Earth Planets Space, 57, 203-207.

Rau, R. J. and F. T. Wu, 1995: Tomographic imaging of lithospheric structures under Taiwan. Earth Planet. Sci. Lett., 133, 517-532.
Shin, T. C. and T. L. Teng, 2001: An overview of the 1999 Chi-Chi, Taiwan, earthquake. Bull. Seismol. Soc. Am., 91, 914-929.

Wang, C. Y., Y. H. Lee, M. L. Ger, and Y. L. Chen, 2004: Investigating subsurface structures and $\mathrm{P}$ - and S-wave velocities in the Taipei basin. Terr. Atmos. Ocean. Sci., 15, 609-627.

Wang, G. Q., G. Q. Tang, D. M. Boore, G. V. N. Burbach, C. R. Jackson, X. Y. Zhou, and Q. L. Lin, 2006: Surface waves in the western Taiwan coastal plain from an aftershock of the 1999 Chi-Chi, Taiwan, earthquake. Bull. Seismol. Soc. Am., 96, 821-845.

Wang, J. H., 2008: Urban seismology in the Taipei metropolitan area: Review and prospective. Terr. Atmos. Ocean. Sci., 19, 213-233, doi: 10.3319/TAO.2008.19.3.213(T).

Wang, J. H. and F. T. Wu, 1989: Numerical particle motions of Rayleigh waves in laterally inhomogeneous media. $J$. Phys. Earth, 37, 325-343.

Wang-Lee, C. M. and T. P. Lin, 1987: The geology and land subsidence of the Taipei Basin. Mem. Geol. Soc. China, 9 , 447-464.

Wu, C. F., W. H. K. Lee, and D. M. Boore, 2008: Strong-motion data from the two Pingtung, Taiwan, earthquakes of 26 December 2006. Terr. Atmos. Ocean. Sci., 19, 595-639, doi: 10.3319/TAO.2008.19.6.595(PT). 